\title{
Resveratrol in vascular diseases and therapeutics
}

\author{
Andrea BALLINI*, Massimiliano Bruno CINQUE, Vittorio DIBELLO and Stefania CANTORE \\ School of Medicine, University of Bari ALDO MORO, Bari, Italy
}

The increased incidence of cardiovascular diseases (CVDs) (atherosclerosis, hypertension, stroke, ischemic heart diseases, heart failure, etc.) will lead to an expected worldwide number of CVDrelated deaths of more than 23.6 million by 2030 [1].

Resveratrol (3,5,4'-trihydroxy-trans-stilbene) (RESV) is a natural polyphenolic compound that exists in Polygonum cuspidatum, grapes, peanuts and berries, as well as their manufactured products, especially red wine.

RESV is mainly found in the grape skin, whereas proanthocyanidins are found only in the seeds, and in plants, its functions as a phytoalexin that protects against fungal infection.

Recent studies have demonstrated that RESV and also proanthocyanidin possesses diverse biochemical and physiological properties, including estrogenic, antiplatelet, and anti-inflammatory properties as well as a wide range of health benefits ranging from chemoprevention to cardioprotection [2].

In fact, it could play a potential protective role against CVDs, and be involved in the "French paradox" characterized by the low incidence of CVDs in the French population despite a high intake of saturated fats, in association with moderate red wine consumption [3].

The specific effects of these polyphenolic compounds found in red wine have been shown to decrease the risk of coronary artery disease by attenuating the oxidation of low density lipoprotein (LDL) [4].

Wine drinkers have higher high density lipoprotein (HDL) levels than that of non-wine drinkers [5]. High HDL levels are known to exert a protective effect against coronary vascular events due to atherosclerosis.

The protective effects of RESV against oxidative injury both in vivo and in vitro are likely to be attributed to the upregulation of endogenous cellular antioxidant systems rather than the direct scavenging activity of reactive oxygen species (ROS) [6].

Besides the vessels, ROS generation also affects the heart. In fact It is well-known that hydrogen peroxide $\left(\mathrm{H}_{2} \mathrm{O}_{2}\right)$ impairs cardiac contraction and evokes cardiac hypertrophy [7].

Cardiac stem cells pre-treated with RESV were also showed better survival, proliferation, and differentiation toward cardiomyocyte in vivo (animal model). Transplantation of these resveratrol-modified cardiac stem cells improved cardiac function even at the end of 4 months [8].

In a one-year randomised, placebo-controlled study assessing secondary prevention of CVDs among people with stable coronary heart disease $(\mathrm{n}=75)$, supplementation with RESV $(8-16 \mathrm{mg} /$ day) was found to improve cardiovascular status (based on biomarkers) [9].
In a similar study among people taking statins for primary CVDs prevention ( $\mathrm{n}=75)$, RESV supplementation $(8-16 \mathrm{mg}$ /day) was found to significantly improve the inflammatory and fibrinolytic status of patients, reducing their risk of CVDs [10].

The anti-thrombosis properties of RESV have been also shown in vivo. Indeed, RESV orally administrated with a high-fat diet in genetically hypercholesterolemic mice (apoE-/-/LDLR-/-) suppressed the formation of atheroma in the aortae and reduced the laser-induced thrombosis in their carotid arteries [11].

Moreover, RESV may improve vascular function by increasing Flow-mediated dilatation, with evidence linking this to the ingredient's ability to increase nitric oxide (NO) concentrations [12].

The antioxidant properties of RESV, that act at multiple levels such as cellular signalling, enzymatic pathways, apoptosis and gene expression, could also represent potential to enhance the current antihypertensive pharmacotherapeutic approaches.

In addition to scavenging ROS, exogenously administered RESV modulates the expression and activity of antioxidant enzymes, such as silent mating type information regulation 2 homolog surtuin (SIRT) 1 , 3and 4, superoxide dismutase (SOD), glutathione peroxidase (GPx), and catalase, either through transcriptional regulation via nuclear factor E2-related factor 2 (Nrf2), activator protein (AP) 1, forkhead box protein $\mathrm{O}$ (FOXO), or through enzymatic modifications [13].

The emerging data from human clinical trials confirms what the past decade of in vitro and laboratory animal models have suggested; RESV has considerable potential to improve health and prevent chronic disease in humans like obesity, cancer, diabetes, vascular and CVDs.

Whereas in case of CVDs, seems that RESV treatment develops protective effects on the cardiovascular system in a preventive way, also because is available in various forms like Resveratrol capsule i.e. $10 \mathrm{mg} /$ day, Resveratrol enriched grape extract i.e. $350 \mathrm{mg} /$ day, Resveratrol rich grape supplement i.e. $8 \mathrm{mg} /$ day, Red grape seed extract i.e. $200 \mathrm{mg} /$ day or red wine consumption between $150-400 \mathrm{ml} /$ day for around 3-6months protects against cardiovascular diseases and its complications. However various doses of RESV supplement are prescribed depending on the disease condition and the degree to which it has affected the body. Thus

Correspondence to: Andrea Ballini, University of Bari ALDO MORO, P.zza Giulio Cesare, 11, 70124, Bari- Italy, Tel/Fax: (+39) 0805448514, E-mail: andrea. ballini@me.com

Key words: resveratrol, cardioprotection, red wine, grapes, polyphenolic, cardiovascular health

Received: January 12, 2017; Accepted: January 17, 2017; Published: January 20, 2017 
RESV intake in moderation on a regular basis helps and is beneficial in metabolic, cardiovascular, mitochondrial and neurological disorders [14].

\section{Declaration of conflicting interests}

The author(s) declared no potential conflicts of interest with respect to the research, authorship, and/or publication of this article.

\section{References}

1. Laslett LJ, Alagona P Jr, Clark BA 3rd, Drozda JP Jr, Saldivar F, et al. (2012) The worldwide environment of cardiovascular disease: Prevalence, diagnosis, therapy, and policy issues: A report from the American College of Cardiology. J Am Coll Cardiol 60: S1-S49. [Crossref]

2. Das DK, Mukherjee S, Ray D (2010)Resveratrol and red wine, healthy heart and longevity. Heart Fail Rev 15: 467-77.[Crossref]

3. Renaud S, de Lorgeril M (1992) Wine, alcohol, platelets, and the French paradox for coronary heart disease. Lancet 339: 1523-1526. [Crossref]

4. Ruf JC (2004) Alcohol, wine and platelet function. Biol Res 37: 209-215.[Crossref]

5. da Luz PL, Coimbra SR (2004)Wine, alcohol and atherosclerosis: Clinical evidences and mechanisms. Braz J Med Biol Res 37: 1275-1295.[Crossref]

6. Spanier G, Xu H, Xia N, Tobias S, Deng S, et al. (2009) Resveratrol reduces endothelial oxidative stress by modulating the gene expression of superoxide dismutase 1 (SOD1), glutathione peroxidase 1 (GPx1) and NADPH oxidase subunit (Nox4). J Physiol Pharmacol 60: 111-116. [Crossref]

7. Rossi GP, Sacchetto A, Cesari M, Pessina AC (1999)Interactions between endothelin-1 and the renin-angiotensin-aldosterone system. Cardiovasc Res 43: 300-307.[Crossref]

8. Gorbunov N, Petrovski G, Gurusamy N, Ray D, Kim DH, et al. (2012) Regeneration of infarcted myocardium with resveratrolmodified cardiac stem cells. $J$ Cell Mol Med 16: 174-184.[Crossref]

9. Tomé-Carneiro J, Gonzálvez M, Larrosa M, Yáñez-Gascón MJ, García-Almagro FJ, et al. (2013) Grape resveratrol increases serum adiponectin and downregulates inflammatory genes in peripheral blood mononuclear cells: a triple-blind, placebocontrolled, one-year clinical trial in patients with stable coronary artery disease. Cardiovasc Drugs Ther 27: 37-48. [Crossref]

10. Tomé-Carneiro J, Gonzálvez M, Larrosa M, Yáñez-Gascón MJ, García-Almagro FJ, et al. (2012) One-year consumption of a grape nutraceutical containing resveratrol improves the inflammatory and fibrinolytic status of patients in primary prevention of cardiovascular disease. Am J Cardiol 110: 356-363.[Crossref]

11. Fukao H, Ijiri Y, Miura M, Hashimoto M, Yamashita T, et al. (2004) Effect of transresveratrol on the thrombogenicity and atherogenicity in apolipoprotein E-deficient and low-density lipoprotein receptor-deficient mice. Blood Coagul Fibrinolysis 15: 441-446.[Crossref]

12. Wong RH, Howe PR, Buckley JD, Coates AM, Kunz I, Berry NM (2011) Acute resveratrol supplementation improves flow-mediated dilatation in overweight/obese individuals with mildly elevated blood pressure. Nutr Metab Cardiovasc Dis 21: 851856.[Crossref]

13. Kitada M, Kume S, Imaizumi N, Koya D (2011) Resveratrol improves oxidative stress and protects against diabetic nephropathy through normalization of Mn-SOD dysfunction in AMPK/ SIRT1-independent pathway. Diabetes 60: 634-643.[Crossref]

14. Battalwar R, Pasad J (2012) A review on benefits of resveratrol on health and diseases especially cardiovascular diseases. Int J Curr Ad Res 4: 537-544.

Copyright: $\odot 2017$ Andrea BALLINI. This is an open-access article distributed under the terms of the Creative Commons Attribution License, which permits unrestricted use, distribution, and reproduction in any medium, provided the original author and source are credited. 